\title{
能源地缘政治与能源权力研究
}

\author{
杨宇 $1,2,3$, 何 则 $1,2,3^{*}$
}

(1. 中国科学院地理科学与资源研究所区域可持续发展分析与模拟实验室, 北京 100101;

2. 中国科学院大学资源与环境学院, 北京 $100049 ; 3$. 粤港澳大湾区战略研究院, 广州 510070)

\begin{abstract}
摘 要: 围绕油气资源的权力博亦仍然是当今世界最主要的能源权力争夺, 但不同时代的能源权力的属性有所不 同, 能源安全与能源战略内涵也有所不同。论文在系统梳理能源地缘政治基础上, 提出了能源权力的概念, 并从地 缘政治格局、能源安全观、能源网络和全球能源治理 4个方面进行了具体阐述。研究认为: (1) 以能源分布、产销空 间变化及其规律性总结是传统能源地缘政治研究的核心, 油气资源地理分布的不平衡性是能源权力产生的最直接 因素。(2) 从石油危机时代到未来新能源时代, 能源安全观的不同是影响国际能源地缘政治权力变化的重要因 素。(3) 能源的商品属性和地缘属性决定了能源贸易不仅是经济行为, 其空间的流动与国际政治关系密切。生产 与消费的分离使得油气二次分配过程中的贸易控制和通道控制对能源权力重构产生重要影响。(4) 全球能源权力 巨变和复杂错综的能源权力网络将引发全球能源治理体系的新秩序。权力的主体从国家、国际组织、跨国公司转 变为全球能源网络中利益共同体, 能源治理的主题从一国之利益走向了全球能源权力的再分配过程。展望未来, 如何在理论上建构新时代的能源权力的理论体系, 深化气候变化和新能源等因素影响下的世界能源权力的演变、 地理空间与权力的相互依赖关系、权力秩序的重构及其效应、全球能源治理机制及其治理模式等研究, 对科学认知 和研判世界能源形势与能源战略的演化具有重要的意义,也是能源地缘政治学研究的重要方向性命题。
\end{abstract}

关 键 词: 能源地缘政治; 能源权力; 能源安全; 能源贸易; 全球能源治理

2018 年美国对伊朗石油禁运引发世界主要石 油消费国的恐慌与仓促应对;2020年初新冠肺炎疫 情蔓延后, 沙特阿拉伯打响了石油价格战, 引发美 股动荡, 直接波及世界能源市场。以油气为代表的 传统能源博亦在新能源方兴未艾之时, 依然是全球 能源地缘政治的核心。2018 年全球化石能源消费 占比高于 $85 \%$, 其中石油和天然气在能源消费中的 比例接近 $60 \%$, 是全球能源市场的主体, 也是新兴工 业化国家最依赖的能源。从地缘属性来看, 煤炭和 太阳能、水电、风能等尚不构成具有大国地缘政治 竹制的战略资源属性, 未来相当长一段时间内, 油 气资源仍然是关系到一个国家的国计民生和国家
安全的核心战略资源 ${ }^{[1]}$ 。油气资源的占有权、控制 权、贸易权、运输安全、消费和投资等,仍然是国家 决策中需要优先考虑的问题, 以油气资源为核心的 传统能源地缘政治依然具有重要的研究价值。有 必要在新旧能源交替之时, 对油气资源为核心的地 缘政治的研究及其未来研究展望进行系统的梳理。

从基本属性来看, 能源本身虽然不具有政治属 性,但能源所具有的稀缺性、不可再生性、地理分布 的不平衡性和经济发展的高度依赖性凸显了能源 的地缘政治属性。即使是新能源, 如风能和太阳能 等虽然表现为资源的遍地性, 但是其装机所依赖的 稀土、钴等稀有元素具有稀缺性与地理分布的不平

收稿日期: 2020-03-17; 修订日期: 2020-06-22。

基金项目: 国家自然科学基金项目(42022007,41871118); 中国科学院青年创新促进会项目(2018069)。 [Foundation: National Natural Science Foundation of China, No. 42022007 and 41871118; Youth Innovation Promotion Association, CAS, No. 2018069. ]

第一作者:杨宇(1984-), 山东威海人,研究员,博士生导师,主要从事能源地缘政治与区域发展研究。

E-mail: yangyu@igsnrr.ac.cn

*通信作者简介: 何则(1992-), 陕西宝鸡人,博士生,主要从事能源经济地理、产业与区域规划研究。E-mail: heze@1zb.ac.cn

引用格式: 杨宇, 何则. 能源地缘政治与能源权力研究 [J]. 地理科学进展, 2021, 40(3): 524-540. [Yang Yu, He Ze. Energy geopolitics and power. Progress in Geography, 2021, 40(3): 524-540. ] DOI: 10.18306/dlkxjz.2021.03.015 
衡性。“争夺稀有资源或分布不均的资源并不是新 现象, 历史上这种争夺常常是引起冲突或战争的原 因” ${ }^{[2]}$ 。不同国家和地区间在能源的生产和消费问 题上自然会发生合作、竞争、冲突甚至战争。尤其是 全球油气资源的分布、生产、消费在地理上的不平衡 性造成了能源经济要素的分离, 即资源与消费的分 离、资本与需求的分离、科技与开发的分离, 从而导 致能源的竞争加剧, 影响着世界政治格局的变化。 从1859年美国宾夕法尼亚石油的商业性开采以来, 能源生产与供应的变化经历了墨西哥湾时代、海湾 时代和中心外围对峙时代。围绕油气资源、市场、通 道的角逐与竞争, 成为国际地缘政治演变研究的重 要内容。剑桥能源研究会主席丹尼尔・耶金1990年 出版的 The Prize: the Epic Quest for Oil, Money and Power ${ }^{[3]}$ 是 20 世纪 90 年代以来国际能源政治界影响 最大的一部著作。他指出, “石油与地缘政治之间的 密切关系, 是其他任何原材料都无法企及的。这一 点在中东、俄罗斯、中国、拉美……万至世界任何地 区都可以得到证实”。基辛格 ${ }^{[4]}$ 在 20 世纪 70 年代发 生的石油危机中指出当今地缘政治博弯中最大的 筹码就是石油, “如果你控制了石油, 你就控制了所 有国家”。Simmon Bromley 在其所著的 American hegemony and world oil: The industry, the state system and the world economy $y^{[5]}$ 中探讨了战后美国领导 下的石油规则和能源战略, 认为大多数的国际关 系理论不足以解释美国霸权, 分析美国霸权应重 点分析作为战略商品的石油。传统的能源地缘政 治研究多是基于此类视角开展的能源安全与能源 合作研究。

时至今日, 随着科技的进步、对原材料的需求、 国内和国际政治目标的变迁, 以及判断追求政治目 标手段的合法性标准的改变, 新的民族国家、跨国 公司、国际组织和地区性的经济组织等国际行为体 的出现, 都导致地缘政治和能源获取手段和目标发 生了深刻变化。能源安全观从能源供应安全逐渐 转向了系统的安全观和相互依存的共同安全观 ${ }^{[6-10]}$, 能源利益相关主体的行为从能源争夺开始走向相 互依存的能源合作关系 ${ }^{[11-15]}$, 将博亦的焦点从油气 资源的控制 ${ }^{[16]}$, 逐步转向资本控制、技术控制和市 场控制等 ${ }^{[17-18]}$ 。非常规能源、风能、太阳能、核能和 电力等用能安全以及环境效应等议题得到广泛关 注 ${ }^{[19-22]}$ 。尤其是气候变化引起了新的全球能源治理 格局的变化, 成为当今世界能源地缘政治格局演变
的新的驱动因子 ${ }^{[23-24]}$ 。与建立在能源实体资源上的 博峦不同,气候变化与全球能源治理使得能源地缘 政治的博亦目标更加多元化, “减排责任” “碳排放 空间”和“低碳壁垒”等能源清洁化利用成为发达国 家新的能源地缘政治博亦的焦点和工具, 各种碎片 化和排他性的全球能源治理的机制, 使得当前世界 能源地缘政治的博弯更加复杂 ${ }^{[23]}$ 。

总之, 无论是西方发达国家与国际石油公司抢 占中东地区石油资源的“红线协定”,还是美国的全 球战略布局与俄罗斯的能源战略东移; 无论是相互 依存与国际能源合作的机制论, 还是从传统到非传 统的能源安全论; 无论是石油输出国、国际能源署 的全球能源市场的协调, 还是未来全球能源治理体 系的构建, 国际重大能源事件的背后都指向了能源 的地缘政治属性及其所衍生的控制其他国家和能 源行为体的能力。

综上所述,在能源地缘政治与能源博弯的过程 中, 隐喻着能源权力的产生与发展过程。即能源权 力是在地理分布不平衡的基础上, 通过对能源的占 有、支配、分配和管理等影响其他国家和行为体的 能力。权力是透视与解析能源地缘政治、能源安 全、国际能源合作与全球能源治理等问题的重要视 角。能源的空间分布、产消格局的空间错位是“权 力” 的空间属性和赖以依存的地理空间; 而产消错 位能源贸易是能源 “权力” 在国家之间的流动, 是权 力的“地点空间”向权力的“流空间”转换; 全球化时 代民族国家、国际组织、国际石油公司等能源行为 体所交织形成的复杂网络,赋予了权力在流空间中 更为广泛的影响力; 而《京都议定书》《巴黎协定》等 气候变化下的“共同而有区别”的全球能源治理体 系, 未尝不是新时代下的治理规则与新的发展权 力。从权力的视角审视世界能源地缘政治的形势, 可以清晰地发现全球范围内建立在传统能源生产 格局基础上的能源权力正在被重新建构,不再以化 石能源的占有权和生产权所产生的“油权”为唯一 核心, 而是拓展到了“能源供应权” “能源需求权”、 “能源技术权” “能源金融权” “能源碳权”及其所引 发的“发展权”等多维能源权力 ${ }^{[25-26]}$ 。权力的关联也 早已超越了单纯的能源竞争与合作关系, 而是表现 为在能源需求、能源结构、国家安全、政策干预、新 能源技术、气候变化和全球能源治理等一系列因素 影响下, 能源生产国、消费国、国际组织、跨国能源 公司等多种利益行为体共同参与、交织形成的复杂 
能源权力关联问题。不同行为体的发展阶段不同 决定了其在能源权力网络中的权力诉求不同, 因此 在全球重大能源事件与能源治理中的角色也必然 不同。已有关于能源地缘政治及能源权力的相关 研究, 主要集中在 4 个方面:一是能源地缘政治格局 及其变化研究; 二是从传统到非传统的能源安全观 研究; 三是能源流动与能源贸易研究; 四是全球能 源治理的相关研究。在这些研究梳理的基础上, 本 文提出未来能源地缘政治研究与能源权力研究的 展望。

\section{1 能源地缘政治格局及其变化}

能源分布、产消空间变化及其规律性总结是传 统能源地缘政治研究的核心。其内核主要表现为 资源归属的控制, 油气资源地理分布的不平衡性是 其权力产生的最直接因素。因此资源的控制权是 最原始也是最直接的能源权力, 是能源地理学和世 界地理学认识能源地缘政治博亦最直观的切人 点。能源地缘政治格局是能源利益相关主体从自 身的利益出发, 通过竞争、合作和谈判等方式, 在能 源的生产、交换、分配和消费等方面, 在一定历史时 期内相互制约而形成的相对稳定而均衡的空间状 态 ${ }^{[27]}$ 。如何调节与优化权力配置格局, 进而在能源 地缘政治格局中谋求有利地位、位置与实现利益最 大化, 是能源利益相关主体权力博弯竞合的主要目 标。油气资源依然是当今世界最重要的战略资源, 在能源供应领域中占据主导地位 ${ }^{[28-29]}, 2035$ 年仍将 占全球能源供应的 $77 \%{ }^{[30]}$, 围绕能源地缘政治格局 的研究从石油危机时代一直持续到近日, 且仍将具 有学术讨论的价值。

石油危机以来, 油气资源的分布、生产、消费、 贸易与运输的基本格局变化加剧了能源的争夺态 势 ${ }^{[1,31]}$ 。从油气供需格局来看, 在中东之外形成了北 美、俄罗斯、中亚、中南美洲、非洲等油气生产中心； 美国超越沙特阿拉伯和俄罗斯成为世界第一大油 气生产国, 逐渐实现 “能源独立” 并迅速增加油气出 口, 全球油气供给呈现出扁平化、离散化的趋势。 油气消费格局呈现出多极分散的趋势, 亚洲成为油 气资源消费增长最快的区域 ${ }^{[32-33]}$ 。产消格局错位导 致了贸易和运输格局变化, 印度洋与西太平洋航线 在油气资源运输中的地位有所增强, 印度洋航线、 马六甲海峡及中国南海的博弯也日趋白热化 ${ }^{[34]}$ 。
伴随着油气资源国的“国有化运动”,资源控制权逐 渐回归到国家石油公司 ${ }^{[25]}$ 。美英等发达国家和国 际石油公司等超国家行为体的能源权力从资源占 有权、生产控制逐渐转向技术、金融、投资和定价等 方面的控制 ${ }^{[35]}$ 。这些重大变化都将对全球能源的 权力体系和能源地缘政治格局产生深远的影响。

在早期地缘政治“零和”博弯思想的指导下,实 力原则和利已主义在国家能源争夺战中被奉为圭 香, 这种权力逻辑导致国际能源秩序长期以来处于 混乱状态。石油危机时代, 能源的权力属性主要表 现为化石能源的有限性和空间不均衡性所产生的 能源归属、加工、运输所构成的基本权力 ${ }^{[36-37]}$, 以此 形成了能源地缘政治的早期博弯和权力的争夺 ${ }^{[38]}$ 。 海湾战争、伊拉克战争、中亚一里海地区的天然气 管线争夺等都直接和间接地反映了油气权力的博 弯 ${ }^{[39-44]}$ 。能源的主权与占有权、勘探与开发权、价格 制定权等关系到一个国家的生存与发展, 能源地缘 政治是国家安全的重要考量 ${ }^{[1,45-46]}$ 。

20 世纪 80 年代后期,世界能源供需市场基本 平衡的状态已经非常脆弱, 结构性失衡突出, 利益 与矛盾相互交织, 世界能源格局不断加速调整 ${ }^{[47-48]}$ 。 世界油气资源生产格局进人了欧佩克(organization of the petroleum exporting countries, OPEC) 与非欧 佩克的对峙时代 ${ }^{[25]}$ 。冷战结束后, 环里海区域、北 非和西非成为新的油气供应源, 以中国、印度为代 表的亚洲发展中国家成为世界油气资源消费的主 力 ${ }^{[49]}$ 。全球石油贸易和油气资源流动方向转向东 亚, 印度洋、马六甲和南海通道的权力争夺对国际 关系格局影响凸显 ${ }^{[34,50-51]}$ 。金融危机之后, 页岩气技 术和新能源技术的商业化,加快了美国“能源自由” 步伐,降低了欧洲对传统能源的依赖。世界能源格 局由传统的能源消费国和能源生产国的“两极格 局”向错综复杂的“多极格局”转变 ${ }^{[10,52-55]}$ 。

\section{2 从传统到非传统的能源安全观}

不同时代的能源权力的属性有所不同, 因此能 源安全观在不同的时代也有不同的认识。从保障 供给安全为核心的石油危机时代,到围绕能源相互 依赖所形成的集团化行动, 再到未来新能源时代的 全球能源治理新秩序, 能源安全观念一直在发生变 化。能源安全观的不同, 导致一国所采取的国际能 源战略出发点及其国家能源博亦行为与策略不同, 
并最终引发国际能源地缘政治权力变化。最明显 的例子就是美国“能源独立”政策对美国国家能源 安全和中东地区动荡的影响。因此能源安全观也 一直成为学术界关于能源地缘政治研究的重要 方面。

1974 年成立的国际能源署(International Energy Agency, IEA)正式提出了以稳定原油供应和价格 为中心的国家能源安全的概念 ${ }^{[5]}$ 。保罗 - 斯塔尔 斯 ${ }^{\left[{ }^{77}\right]}$ 对传统能源安全理论观点进行了归纳, 认为传 统能源安全关注现存的能源供应协议突然中断、瓦 解等引起的安全威胁。政治动荡、经济威胁、军事 冲突以及恐怖袭击这些潜在的安全威胁是最需要 关注的。第一次石油危机爆发后, 石油供应不足导 致西方世界经济动荡, 能源进口国与出口国之间的 关系引起了更为广泛的关注和讨论, 能源供应的保 障成为能源安全问题的核心 ${ }^{[58]}$ 。传统的能源安全 论认为由于主体性的不同, “能源安全”可以分为能 源供应安全和能源需求安全。从能源生产国或出 口国的角度进行定义, 能源安全就是“持续需求安 全” ${ }^{[59]}$ 。对于能源消费国或者进口国而言, 能源安 全就是 “以一种不中断经济进程的方式和合理价格 水平满足需求” ${ }^{[60]}$ 。斯德哥尔摩的国际和平研究所 发表了专题报告《石油与安全》 ${ }^{[2]}$, 提出了系统的能 源安全观。系统的能源安全观不只是考虑能源供 需的安全问题, 而是从政治、经济和军事等各个角 度考察能源安全对区域的影响 ${ }^{[61-64]}$ 。美国 2001 年 颁布的《国家能源政策》认为, 能源安全战略包括能 源来源的多元化、加强与伙伴国家和盟国在能源应 急合作和推动能源供应国制定 “负责任” 的能源生 产政策 ${ }^{[65]}$ 。

20 世纪 70 年代的石油危机也促使西方国家认 识到了“一个并不称心如意但却更为对称的相互依 存的存在” ${ }^{[38]}$, 相互依存理论成为国际学术界认识 石油危机、探讨能源安全的主要理论工具, 能源安 全观从一国的范围拓展到相互依存的能源集团行 为。产油国开始在一体化日益深化的国际原油市 场发挥作用, 以“七姐妹” 所代表的美欧跨国石油公 司为中心的旧国际石油机制被破坏, 西方国际石油 资本丧失了对产油国的控制权。罗伯特-布莱斯在 《能源独立之路》 ${ }^{[6] 1}$ 中指出 “谈到能源, 美国的未来 及其在政治、经贸和环境方面的未来, 美国必须接 受能源相互依存的现实”。石油出口国和进口国在 能源上形成的相互依存关系, 使双方认识到在保持
国际经济、军事稳定方面存在共同利益。罗伯特. 基欧汉(Robert Keohane) 等 ${ }^{[67]}$ 认为, 能源政治尤其是 在能源安全问题上,国家机制不仅能防止国际能源 关系的无政府状态, 而且能有效促进处于相互依存 的世界能源领域的国际合作。与其将能源视为冲 突的源泉, 不如重视能源所具有的促进一体化, 以 及创造更广泛的利益共享与合作范围的能力 ${ }^{[1]}$ 。 《理解国际冲突: 理论与历史》奛一书中, 小约瑟夫 奈精辟地分析了石油危机中相互依存因素的关键 作用; 基欧汉在《权力与相互依赖》 ${ }^{[68]}$ 中, 分析了相 互依存对世界能源领域国际合作机制的重要影响。

同时, 冷战之后国际关系的变化、能源安全研 究视角的转变和研究议程的拓展,使得能源安全的 内涵和外延发生了意味深远的扩展,包括环境挑 战、日益增强的市场支配力量等诸多相互影响、相 互制约的因素 ${ }^{[33,69]}$ 。世界能源理事会 1995 年在《世 界能源评估》报告 ${ }^{[70]}$ 中指出, 当今的能源安全概念 需要引人更多的因素, 它包括环境挑战、日益增强 的市场支配力量等,这些要素是相互影响、相互制 约的。保罗・斯塔尔斯 ${ }^{\left[{ }^{77}\right]}$ 认为, 非传统的能源安全 观最为关注的是, 当前能源政策对于人类福利以及 地球生态系统的影响,其中包括 2 个核心问题:一方 面, 非传统能源安全关注能源资源的开发、生产、运 输、储存和分配等方面发生事故的潜在威胁; 另一 方面,关注能源消费引起的环境效应。2007年欧盟 委员会发展及与非加太关系总司官员白小川等 ${ }^{[19]}$ 从非传统能源安全观的视角发表了富有启迪的能 源安全思想,提出政策制度层面的抉择,不仅决定 美、中、欧三角关系中的能源安全博弯结果, 也影响 环境、气候和人类安全等全球性问题的解决前景。

在中国快速的工业化和城镇化进程中, 能源供 应保障是国家能源安全的基本目标所在 ${ }^{[7]}$, 保障石 油数量和价格稳定是中国石油安全的核心 ${ }^{[72-75]}$ 。随 着中国市场经济的发展, 能源安全问题的解决之道 更复杂, 国家、地区和国际组织的影响力和控制力 是石油地缘政治格局的决定因素,需要市场、外交、 军事和经济安全的综合性一揽子政策和措施 ${ }^{[76-77]}$ 。 20 世纪 90 年代以来,世界能源安全格局发生了一 系列变化,中国所面临的能源安全问题与战略目标 随之转变 ${ }^{[78-79]}$ 。2 2 世纪中国面临能源安全问题主要 包括: 进口依赖度的不断攀高, 国内石油战略储备 不足, 外贸结构没有明显改善, 运输通道过于单一, 能源供给稳定性较低, 主要能源进口国政治动荡频 
繁 ${ }^{[10,43,80-82]}$ 。为此学者们探讨了不同尺度下能源安全 研究的理论与方法 ${ }^{[83-84]}$, 研究了中国应对能源安全 的对策 ${ }^{[85]}$, 提出中国能源安全问题的关键是通过多 种渠道全力开拓国内外石油资源, 以资源国际化为 原则, 实施“走出去”战略, 建立国家战略石油储备, 开展双边和多边合作等 ${ }^{[86-87]}$, 并对中国与中东、中 亚、俄罗斯、非洲、中南美洲的能源外交和能源合作 模式等进行了研究 ${ }^{[25,88-91]}$ 。然而, 日趋严峻的能源地 缘政治格局加剧了中国海外能源合作的风险。中 国的海外能源供给不仅受到美国等西方大国的地 缘政治汼制 ${ }^{[92]}$, 也面临着日本、印度等消费大国的 激烈竞争 ${ }^{[93]}$ 。中国海外能源供给主要来源中东、中 亚等地区, 长期面临着复杂动荡的国际与区域局 势, 来源的稳定性和风险较大 ${ }^{[32]}$ 。海上能源运输通 道北印度洋航线、马六甲海峡和中国南海面临着复 杂的国际政治博弯和领土争端。能源民族主义抬 头, 成为地区资源争夺和地缘政治冲突的重要源 头, 加剧了中国海外能源开发与合作的风险 ${ }^{[94]}$ 。严 峻的形势使得中国在世界能源权力体系中面临巨 大的能源安全诉求 ${ }^{[36]}$ 。

\section{3 从“地点空间”转向“流空间”的能源 网络}

能源的商品属性和地缘属性决定了能源贸易 不仅是经济行为, 其空间的流动与国际政治关系密 切。生产与消费的分离使得油气二次分配过程中 的贸易控制和通道控制对能源权力重构产生重要 影响。贸易与通道控制权影响和控制着全球能源 的再分配, 产生能源地缘政治的影响和战略牵制。 “地点空间”上产生的权力通过国际能源贸易逐步 向 “流空间” 的权力转变研究, 是经济全球化下能源 权力研究的新命题。20世纪 90 年代以来, 国际油 气贸易关系不断趋于复杂化, 世界油气贸易的多极 化特征日趋明显。不同产能国与消费国之间、消费 国与消费国之间、生产国与生产国之间围绕着油气 贸易展开了激烈的博弯。总体而言, 油气消费国为 保证供给安全不断地推动油气进口来源多元化, 而 油气生产国为获得稳定的油气财政不断的推动油 气出口多元化,形成了以美国、欧盟、日本和中国等 油气消费国和加拿大、沙特阿拉伯、俄罗斯、委内瑞 拉、安哥拉、墨西哥、阿联酋、伊拉克、阿曼、卡塔尔、 挪威、伊朗和土库曼斯坦等油气生产国为核心的复
杂油气贸易网络 ${ }^{[95]}$ 。近年来, 能源贸易研究已由静 态统计转向动态演化, 网络成为全球能源贸易的重 要研究视角和研究方法。借助于复杂网络分析方 法, 能源贸易的新特性和拓扑特征得以被揭示 ${ }^{[96-99]}$ 。

从石油和天然气贸易来看, 学者们通过复杂网 络与空间分析相结合的方法, 发现世界原油贸易网 络具有典型的“小世界”(small and flat worlds)的特 征 ${ }^{[95]}$,地缘政治关系和外交关系是影响区域原油贸 易的主要因素 ${ }^{[100]}$ 。国际石油贸易网络整体容量不 断扩大且国家间的贸易趋于紧密并逐渐形成稳定、 有向和一体化的趋势 ${ }^{[101-104]}$ 。地理距离相近的进口 国倾向于选择类似的贸易伙伴 ${ }^{[103]}$ 。共同贸易伙伴 与双边关系是国际原油贸易的结构性联系动机之 一, 代表了贸易关系的可能性拓展 ${ }^{[105-107]}$ 。海外投 资、技术进步和能源效率也对石油贸易产生了重大 影响 ${ }^{[108-109]}$ 。国际石油贸易网络社团稳定性在演变 过程中有 2 个转折点, 分别是 2004-2005 年的伊拉 克战争和 2008 年金融危机 ${ }^{[110]}$ 。短期尺度上贸易量 对国际石油贸易网络的稳定性具有重要作用 ${ }^{[111]}$ 。 欧洲、美国和中国在世界石油贸易网络中对其他国 家影响显著 ${ }^{[112-113]}$ 。亚太地区在竞争格局演变中的 作用日益突出, 非经济合作与发展组织(organization for economic co- operation and development, OECD)国家已成为全球竞争强度增长的主要推动 力 $^{[114-115]}$, 中国在全球原油贸易中的控制能力在不断 提升, 由局部地缘供给依赖转变为多元共存的贸易 模式 ${ }^{[110,116-118]}$ 。国际天然气贸易网络存在幕律性和 群簇性,网络的异质化程度较高, 局部表现出聚集 性与核心一边缘结构 ${ }^{[119]}$ 。液化天然气(liquefied natural gas, LNG)和管道天然气的进出口贸易网络均 显示无标度分布, 而 LNG 贸易网络中的国家与管道 燃气交易网络的关联度更大, 北美、欧洲和亚洲的市 场尚未整合 ${ }^{[120]}$ 。管道天然气贸易主要集中在欧亚 大陆, 其对战略通道具有路径依赖性和滞后性, 区域 资源禀赋是“核心一边缘”结构的主要成因 ${ }^{[121]}$ 。一 带一路”倡议提出后,丝绸之路经济带沿线国家天然 气贸易格局存在 “马太效应”, 俄罗斯、卡塔尔、新加 坡和中国是天然气贸易的核心国 ${ }^{[122]}$; 然而天然气贸 易互动并不明显, 且由于外部环境的稳定性较差, 核 心一边缘结构不断发生着重组与变更 ${ }^{[123]}$ 。此外, 也 有学者对世界天然气竞争网络、网络优化和模拟分 别进行了研究 ${ }^{[124-126]}$ 。

地理的分离与贸易联系使得国际重要战略通 
道成为能源地缘政治博亦的筹码。马六甲海峡、霍 尔木兹海峡、印度洋航线等全球重要的石油战略通 道成为大国博亦的焦点地区, 最重要的能源运输通 道均有美国海军部署 ${ }^{[34]}$ 。横跨亚欧大陆的众多陆 地能源运输管道争夺也同样面临俄罗斯、美国和欧 盟等的激烈博弯。控制能源的贸易和运输, 也就扼 制住了能源咽喉与经济发展的生命线, 这也是东亚 国家极力摆脱马六甲困境、美伊石油禁运和海湾战 争要力保霍尔木兹海峡的关键原因所在。2018 年 美国对伊朗石油禁运中, 霍尔木兹海峡的超紧张状 态成为影响世界能源供给安全的最大隐患 ${ }^{[127]}$ 。同 样对于中国而言, 石油运输安全成为世界能源买方 市场下中国能源供给安全最薄弱的环节, 学者们研 究了东南亚、东北亚、南亚和中亚等重点区域能源 运输路线的地缘政治格局, 并对马六甲海峡、北印 度洋航线、俄罗斯石油天然气管道等面临的风险等 进行分析, 认为印度洋航线在全球能源博亦中战略 地位日渐凸显 ${ }^{[3,128-129]}$ 。随着大数据技术挖掘与分析 技术在国际航运中的应用, 学者们基于油船轨迹数 据通过交通路径、贸易量、运输网络等对全球原油 海运进行了精细化研究 ${ }^{[130]}$, 并设计了能源运输骨干 网络识别与港口影响力传播的线性阈值模型, 发现 了世界能源运输的“Hub-Spoke”(轮辐式)结构和港 口影响力的级联效应, 定量评估了世界原油港口的 影响力传播路径, 中国原油港口属于尽端式港口, 影响力有限 ${ }^{[131-132]}$ 。从港口尺度, 学者们对俄罗斯东 北航道沿线港口、“一带一路”沿线港口的发展潜力 以及中国沿海港口的运输职能等进行了深人的分 析, 提出了海外港口战略的布局等措施 ${ }^{[133-136]}$ 。

新能源贸易极大地重塑了既有的世界能源贸 易版图。近年来, 中国积极发展新能源, 以应对全 球气候变化和油气能源供应风险, 并成为全球新能 源发展的领导者。风电累计装机量、光伏装机总 量、水力发电等均位居全球第一, 其中太阳能相关 产品贸易占世界的 $42 \%{ }^{[137]}, 2017$ 年全球水电净增长 全部来自中国,全球在建核能中 $40 \%$ 来自中国 ${ }^{[138]}$ 。 学者们以太阳能和水能的贸易网络为切人点研究 了全球新能源网络的变化特征, 认为新能源网络比 油气资源贸易更为复杂 ${ }^{[139]}$ 。相比石油贸易, 新能源 贸易模式发生了变化, 以中国为代表的发展中国家 成为全球新能源贸易的核心 ${ }^{[137]}$ 。学者们还通过综 合能源网络研究, 发现天然气贸易网络相比煤炭、 石油网络具有更大的群落和稳定性 ${ }^{[140]}$, 太阳能光伏
贸易比化石能源贸易要更为密集 ${ }^{[141]}$ 。在综合能源 网络中贸易集团和组织发挥着重要作用,亚太国家 贸易集团具有不确定性 ${ }^{[142-143]}$ 。这些能源贸易与运 输的结构性变化都将影响新一轮能源地缘政治的 博弯问题。

\section{4 全球能源治理与能源权力秩序重构}

全球能源权力巨变和复杂错综的能源权力网 络将引发全球能源治理体系的新秩序 ${ }^{[144]}$ 。以往的 能源治理主要表现为消费国与生产国等国家联盟 为主, 以共同实现国家在能源供给或者能源消费方 面的集中应对,比如欧美发达国家为应对石油消费 安全成立的国际能源署和以产油国为主的协调石 油生产与供应的欧佩克。然而, 在当前全球能源博 弯的形势下, 能源的权力秩序主要体现为既得利益 者和潜在利益者之间的博峦过程及其形成的新权 力体系。在经济全球化和全球气候变化的宏观背 景下,权力的秩序主要表现为 2 个方面:一是权力的 主体结构发生了变化,不再表现为美国等超级大国 及其盟国主导下的单方面利益博弯,而是能源生产 国、消费国、国际组织、跨国能源公司等多种利益行 为体共同参与、交织形成的复杂网络过程,任何国 家都不可能在复杂的全球能源网络中独善其身;二 是全球气候变化与能源清洁转型背景下, 能源治理 的主题已经不仅是国际能源市场中消费国与生产 国集团的权力配置，而是从对抗走向了“共同而有 区别”的减排责任，国际碳排放空间的分配和争夺 等新因素成为能源治理的重要因素。

全球能源治理的核心任务是各国政府和国际 组织制定和实施一系列规则以防止能源相关问题 扩散成为国际性危机，其目标在于利益相关各方实 行集体行动, 采取切实可行的能源政策 ${ }^{[145-147]}$ 。然而 能源利益相关主体的利益诉求不同、矛盾错综复 杂, 深陷能源霸权与能源主权利益之中, 往往难以 达成一致的治理方案 ${ }^{[148]}$ 。因此全球能源治理表现 为一个目标多元、主体分散、结构多层、机制碎化、 领域交叉的治理网络 ${ }^{[149-150]}$, 且尚未形成综合性、权 威性、有约束力的全球能源治理机制 ${ }^{[146]}$ 。目前既有 的能源治理平台与行动框架呈现出发展不成熟、区 域化趋向和偏重消费方的实际不足,导致全球治理 实践进展迟滞、参与主体有限、运行机制不畅的发 展困境 ${ }^{[151]}$ 。针对全球能源治理存在的问题, 学者们 
研究了全球能源治理的动因、治理结构、核心要素、 面临的挑战以及改革趋势等 ${ }^{[152-154]}$ 。

2017 年 6 月美国宣布退出《巴黎气候协定》, 更 是对全球能源治理体系提出了挑战 ${ }^{[155]}$ 。在全球能 源形势深刻变化的大趋势下, 国际社会更应建立采 取集体行动的应对机制 ${ }^{[147]}$ 。全球能源治理模式应 从以国家为中心的传统治理结构向复杂的多层治 理网络转变, 在现有能源治理机制基础上, 应尽可 能吸纳新兴经济体和非国家行为体广泛参与 ${ }^{[156]}$, G20有望发展成为全球能源治理的协调中心, 但面 临着自身机制性缺陷、技术劣势和诸多外在因素制 约 ${ }^{[157]}$ 。目前, 世界上尚缺乏有中国全面参与的真正 意义的全球国际能源组织。中国在世界能源市场 话语权和在全球能源治理体系中的影响力与其经 济、政治的影响力不相称 ${ }^{[150,158-159]}$ 。中国一直积极倡 导参与全球能源治理并加人全球性国际能源组织以 及综合性、区域性国际组织的能源议题讨论 ${ }^{[160-161]}$ 。 如何在错综复杂的能源权力网络中, 持续扩大在全 球能源合作中的影响力和话语权, 是中国深度参与 全球能源治理面临的巨大挑战。

\section{5 研究展望}

全球能源形势正在发生深刻改变, 能源权力正 在被重新建构, 能源的权力关联也早已超越了单纯 的能源竞争与合作关系, 而是表现为多种利益行为
体共同参与、交织形成的复杂能源权力关联问题, 在系列重大能源事件与新能源发展的影响下, 全球 能源地缘政治格局将更加复杂。展望未来,一方 面, 要注重在已有能源地缘政治理论基础上,加强 新时代能源安全与能源权力理论的研究。探讨新 因素影响下的世界能源权力的演变、地理空间与权 力的相互依赖关系、权力秩序的重构及其效应等 方面的研究, 科学认知和研判世界能源权力演化 的基本规律, 是能源地缘政治学研究的重要方向 性命题。另一方面, 能源地缘政治是带有战略性 的宏观议题, 随着大数据与模拟技术的应用, 要注 重在已有研究基础上进行研究尺度的下沉, 如对 能源运输通道的研究应从重要通道地缘形势的宏 观研究下沉到港口尺度的精细化研究, 提升战略 应对的针对性。

具体来看,在理论与技术方法体系的完善基础 之上,一是能源权力的关联研究要从贸易与供给网 络, 拓展到多维权力相互关联的复杂网络研究; 二 是在贸易与运输研究方面, 要进行尺度的下移, 拓 展到运输网络、港口组织及关键风险节点进行研 究; 三是能源地缘格局的研究, 要从地缘格局的变 化规律拓展到重大能源事件所引发的不确定性能 源地缘格局的模拟与重构研究; 四是能源安全思维 与国际能源战略模式的研究, 要从国家联盟进行尺 度上移, 拓展到全球能源治理体系的研究。已有主 要研究内容与未来拓展方向见图 1。

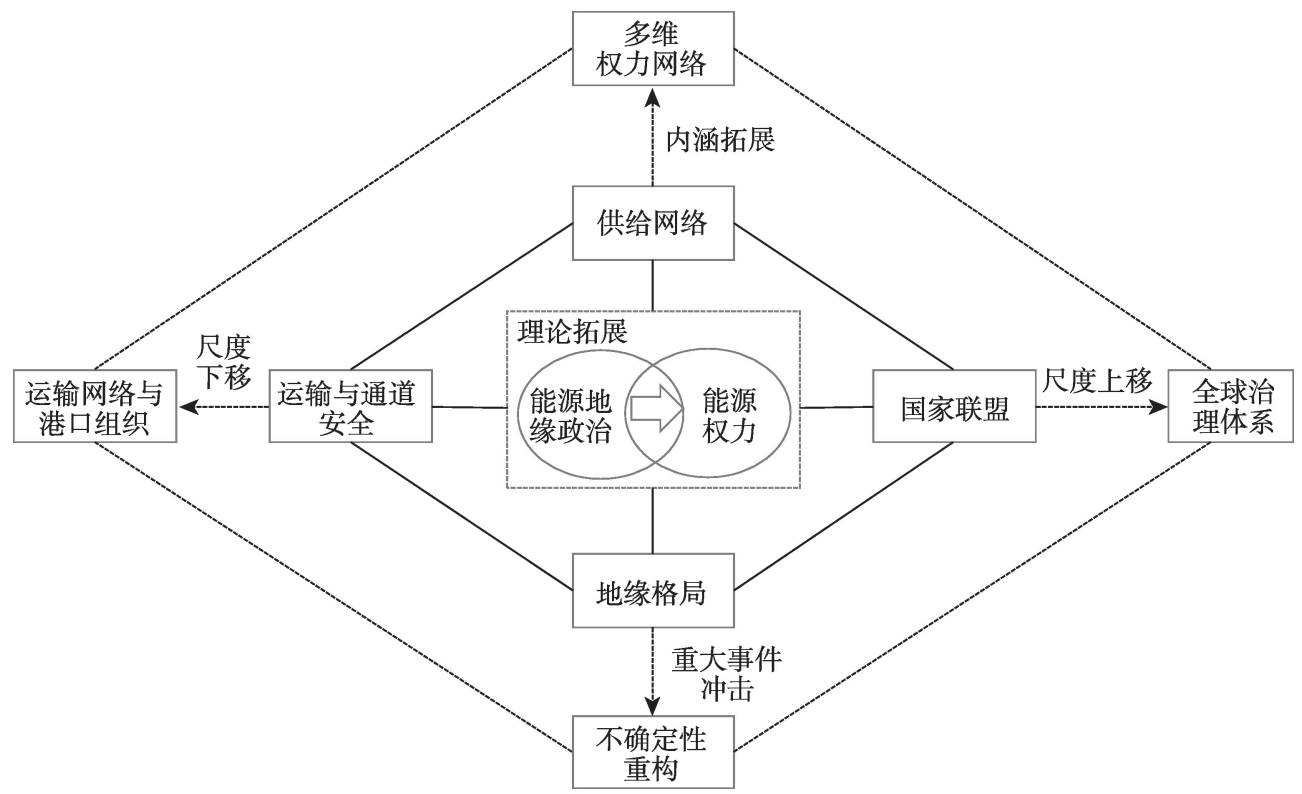

图 1 能源地缘政治与能源权力研究展望

Fig.1 Framework of energy geopolitics and energy power research 


\section{1 多维能源权力的理论建构}

世界能源的权力内涵和外延发生了深刻的转 变。一方面, 传统油气资源依然是当今世界最重要 的战略资源, 但是油气资源的权力结构发生了深刻 变化,能源权力的主体逐渐向 “能权” 的联合体转 变, “能权”之争从能源大国的博峦逐步转换为利益 集团的集体行动。能源安全观念也从能源供应安 全逐渐转向了系统的安全观和相互依存的共同安 全观, 能源消费从传统化石能源资源转向为非常规 能源、核能和电力等用能安全。对权力的控制也逐 渐从资源的控制、通道的控制逐渐向能源投资控 制、能源技术控制和市场控制等方向转变, 能源权 力不再表现为一国或者某一能源集团的利益, 而是 全球能源生产网络、消费网络和投资网络交织下的 利益共同体权力再分配的过程。另一方面, 全球能 源消费结构发生了重大变革, 新能源对油气资源的 替代效应逐渐凸显。世界经济绿色化、能源结构低 碳化乃至无碳化是大势所趋, 天然气、风能、太阳能 等清洁能源需求将显著增加, 煤炭、石油需求增长 将相对放缓。在新的全球能源形势下, 能源权力拓 展到了能源供应权、能源需求权、能源技术权、能源 金融权、能源“碳权”及其所引发的发展权等多维 “能权”。在此背景下, 需要聚焦新时代的能源权力 体系的理论构建, 剖析权力的新内涵以及权力之间 的相互衍生与相互替代关系。

\section{2 复杂能源权力网络及其运行机制的研究}

既有相关研究在理论演绎与定性研究的基础 上, 逐渐在数据统计和指标体系评价等方面, 不断 做出了更新与改进, 并得出了一系列有价值的研究 成果。然而, 已有研究多以能源供需和贸易为权力 的核心, 缺乏对经济全球化、新能源发展和全球能 源治理等因素影响下的多维复杂能源权力的综合 考量。事实上, 无论何种能权, 其产生与流动均嵌 人在复杂的能源权力网络中, 而目前相关研究多关 注能源贸易的网络关系, 一定程度上忽视了当前已 经形成的多种能源利益主体相互关联、互动反馈的 权力关联网络研究。对多主体与多因素共同作用 下的能源网络的稳定性、不同影响因素的传导模式 和运行机制、能源网络的组织机理与运行风险评估 等方面研究相对薄弱。迫切需要以能源权力及其 相互关联为切人点, 构建多层次、多主体、多要素的 能源权力网络, 研究网络的结构、功能、组织模式、 权力传导路径和运行机制, 解析全球多元能源权力
属性及其权力关联关系、权力网络的结构功能和组 织模式、影响因素和运行机制。

\section{3 能源安全通道与战略节点的研究}

全球能源运输通道的安全性一直是能源地缘 政治博弯的重要方面。已有研究对全球能源战略 通道及其地缘形势进行了较为系统的研究, 未来研 究要注重研究尺度的下沉和大数据的应用, 以提高 能源运输安全的精准性和科学性。第一,加强大数 据挖掘技术在能源运输研究中的应用, 实时动态监 测能够极大提升能源实际运输线路与风险节点的 精准化识别, 基于实时能源运输轨迹的动态监测和 仿真模拟是未来研究的重要方向。第二, 能源运输 安全的研究从安全通道的宏观研究下沉到港口尺 度的研究, 通过地理大数据与能源运输数据相结 合, 对不同港口能源运输功能、运输效率及其运输 线路优化提供更为科学的认识。尤其是, 对港口的 发展潜力与风险性评估对中国印度洋战略节点建 设和海洋运输安全具有重大意义。第三, 北极航道 的开通或将改变目前的全球战略运输通道格局,未 来北极航道对现有石油运输线路的替代性、对全球 能源运输网络的影响也是重要的研究议题。

\section{4 重大能源热点事件的权力传导机制与模拟研究}

能源权力的发生和传导必然嵌人在一定地理 空间中, 尤其是能源热点地区和能源热点事件的权 力产生、变化与权力转移都依赖于地理空间。在具 象的地理空间和能源事件中, 能源权力被细化、权 力传导更直接、权力影响因素更加具体, 且直接影 响到一国的能源行为和能源安全。如美国“能源独 立”必然引发全球能源供需格局转变, 尤其是中东 地区能源权力再分配, 中国、日本、印度、韩国和欧 盟国家等能源消费国在中东的权力关系也将发生 连锁反应。再如中国的“一带一路”倡议提出的 “加 强能源基础设施互联互通合作,共同维护输油、输 气管道等运输通道安全……加强能源就地加工转 化”等国际能源合作的内容必将改变中亚的能源权 力构成与权力网络。2020年初新冠肺炎疫情曼延 导致全球能源消费骤减, 与此同时,沙特阿拉伯与 俄罗斯发起能源价格战, 两者的叠加效应导致全球 能源市场出现剧烈动荡, 引发世界能源供需格局的 变化。这些重大突发事件与全球能源供需之间的 关系, 加剧了全球性的能源权力嬗变, 对未来能源 局势影响深远。需要有针对性地加强重大能源热 点事件的权力传导机制与模拟研究。为此, 可以借 
助大数据的手段、政策模拟的工具等,对能源开发、 地缘政治、经济发展、国际投资、油气管道、贸易关 系、新能源发展等方面的权力博弯过程和权力关联 变化进行模拟分析, 提升能源权力结构和能源权力 网络重塑的科学性预判。

\section{5 全球能源治理机制及其治理模式研究}

广泛参与的全球能源治理机制是未来全球能 源权力博弯的重要平台。既有的全球能源治理平 台与行动框架面临着一系列的问题与挑战, 导致全 球治理实践进展迟滞, 相关研究也比较零散, 从学 术上探讨具有全球接受力和约束力的能源机制、重 要的治理平台、治理议题与治理模式是未来研究的 重要方向。从当前来看, 未来要聚焦的重大能源治 理议题包括:一是聚焦 $\mathrm{G} 20$ 的能源治理议题可能引 发的能源利益相关主体的权力博亦和折冲, 阐述 G20 全球能源治理行为对不同能源利益相关主体 能源权力的约束和影响程度, 对于应对能源环境挑 战、打造可持续未来并逐步推进全球能源治理机制 完善;二是在全球变暖背景下, 北极的能源事件的 权力体系构建与制度建设; 三是国家治理的责任与 国家自主贡献(nationally determined contributions, $\mathrm{NDCs}$ ), 这是实现全球气候变化下的控温目标与联 合国 2030 年可持续发展目标(SDG2030)的关键, 同 时也是发展中国家与发达国家关于未来发展权的 争议所在。学界应在全球治理机制与模式上率先 开展相关研究, 为新的全球能源治理体系建设提供 科学的依据。

\section{参考文献(References)}

[1] 余建华, 等. 世界能源政治与中国国际能源合作 [M]. 长 春: 长春出版社, 2011. [Yu Jianhua, et al. World energy politics and China's energy international cooperation. Changchun, China: Changchun Press, 2011. ]

[2] 博-黑恩贝克. 石油与安全 [M]. 俞大畏, 等译. 北京: 商 务印书馆, 1976. [Haenbeck B. Oil and security. Translated by Yu Dawei, et al. Beijing, China: Commercial Press, 1976. ]

[3] Yergin D. The prize: The epic quest for oil, money and power [M]. New York, USA: Simon \& Schuster, 1990.

[4] 亨利・基辛格. 大外交 [M]. 顾淑馨, 林添贵, 译. 海口: 海 南出版社, 1998. [Kissinger H. Diplomacy. Translated by Gu Shuxin, Lin Tiangui, et al. Haikou, China: Hainan Publishing House, 1998. ]

[5] Bromley S. American hegemony and world oil: The industry, the state system and the world economy [M]. Univer- sity Park, USA: Pennsylvania State University Press, 1991.

[6] Nunn S, Schlesinger J R, Ebel R E. The geopolitics of energy into the 21 st century [R/OL]. Washington D C, USA: Center for Strategic and International Studies, 2002-0816 [2020- 06- 10]. https://www.csis.org/analysis/geopolitics-energy-21st-century.

[7] 申玉铭. 经济全球化与国家能源安全 [J]. 世界地理研 究, 2003, 12(3): 78-83. [Shen Yuming. Economic globalization and the national energy security. World Regional Studies, 2003, 12(3): 78-83. ]

[8] Downs E S. The Chinese energy security debate [J]. The China Quarterly, 2004, 177: 21-41.

[9] Yergin D. Ensuring energy security [J]. Foreign Affairs, 2006, 85(2): 69-82.

[10] 史丹. 全球能源格局变化及对中国能源安全的挑战 [J]. 中外能源, 2013, 18(2): 1-7. [Shi Dan. Changes in global energy supply landscape and implications to China's energy security. Sino-Global Energy, 2013, 18(2): 17. ]

[11] Manning R A. The Asian energy factor: Myths and dilemmas of energy, security and the pacific future [M]. London, UK: Palgrave Macmilla, 2000.

[12] 余建华, 戴轶尘. 多维理论视域中的能源政治与安全观 [J]. 阿拉伯世界研究, 2012(2): 107-120. [Yu Jianhua, Dai Yichen. Energy politics and security concept from multidimensional perspectives. Arab World Studies, 2012 (2): 107-120. ]

[13] 刘立涛, 沈镭, 刘晓洁. 能源安全研究的理论与方法及 其主要进展 [J]. 地理科学进展, 2012, 31(4): 403-411. [Liu Litao, Shen Lei, Liu Xiaojie. Theories, methods and progress of energy security research. Progress in Geography, 2012, 31(4): 403-411. ]

[14] 罗伯特·基欧汉. 霸权之后: 世界政治经济中的合作与 纷争 $[\mathrm{M}]$. 上海: 上海人民出版社, 2006. [Robert K. After hegemony: Cooperation and dissension in the world political economy. Shanghai, China: Shanghai People's Publishing House, 2006. ]

[15] 洪菊花, 骆华松, 梁茂林. 主体间性视角下的“一带一 路”能源安全共同体研究 [J]. 世界地理研究, 2017, 26 (2): 11-19. [Hong Juhua, Luo Huasong, Liang Maolin. Research on the "One Belt and One Road Initiative" energy security community under the perspective of inter-subjectivity. World Regional Studies, 2017, 26(2): 11-19. ]

[16] Engdahl W. A century of war: Anglo-American oil politics and the new world order [M]. Michigan, USA: Pluto Press, 2004.

[17] Yetiv S A. Crude awakenings: Global oil security and 
American foreign policy [M]. Ithaca, USA: Cornell University Press, 2004.

[18] Tordo S. National oil companies and value creation [M/ OL]. World Bank Publications, 2011-07-01 [2020-0610]. https://elibrary.worldbank.org/doi/pdf/10.1596/9780-8213-8831-0.

[19] 白小川, 洪建军, 徐力源. 能源安全: 欧美中三角关系中 的一大难题 [J]. 现代国际关系, 2007(10): 44-51. [Bai Xiaochuan, Hong Jianjun, Xu Liyuan. Energy security: A Bermuda triangle for EU-US-China relations? Contemporary International Relations, 2007(10): 44-51. ]

[20] 王文涛, 刘燕华, 于宏源. 全球气候变化与能源安全的 地缘政治 [J]. 地理学报, 2014, 69(9): 1259-1267. [Wang Wentao, Liu Yanhua, Yu Hongyuan. The geopolitical pattern of global climate change and energy security issues. Acta Geographica Sinica, 2014, 69(9): 1259-1267. ]

[21] IEA. World energy outlook 2015 [R/OL]. Organization for Economic Co-operation and Development, 2015-1101 [2020-06-10]. https://www.iea.org/reports/world-energy-outlook-2015.

[22] 王礼茂, 牟初夫, 陆大道. 地缘政治演变驱动力变化与 地缘政治学研究新趋势 [J]. 地理研究, 2016, 35(1): 313. [Wang Limao, Mou Chufu, Lu Dadao. Changes in driving forces of geopolitical evolution and the new trends in geopolitics studies. Geographical Research, 2016, 35(1): 3-13. ]

[23] Wang L M, Gu M C, Li H Q. Influence path and effect of climate change on geopolitical pattern $[\mathrm{J}]$. Journal of Geographical Sciences, 2012, 22(6): 1117-1130.

[24] 巢清尘, 张永香, 高翔, 等. 巴黎协定: 全球气候治理的 新起点 [J]. 气候变化研究进展, 2016, 12(1): 61-67. [Chao Qingchen, Zhang Yongxiang, Gao Xiang, et al. Paris agreement: A new start for global governance on climate. Climate Change Research, 2016, 12(1): 61-67. ]

[25] 杨宇. 全球石油资源开发利用格局演变与中国海外石 油合作模式研究 [D]. 北京: 中国科学院大学, 2013. [Yang Yu. The evolution of global oil resources development and utilization pattern of China's overseas crude oil cooperation model. Beijing, China: University of Chinese Academy of Sciences, 2013. ]

[26] 许勤华. G20 后再发力 [J]. 能源评论, 2017(2): 46-47. [Xu Qinhua. Making more efforts after the G20 meeting. Energy Review, 2017(2): 46-47. ]

[27] 崔守军. 能源大冲突: 能源失序下的大国权力变迁 [M]. 北京: 石油工业出版社, 2013. [Cui Shoujun. Energy conflict: Power transition of big countries in a chaotic energy order. Beijing, China: Petroleum Industry Press, 2013. ]
[28] IEA. World energy outlook 2017 [R/OL]. Organization for Economic Co-operation and Development, 2017-1101 [2020-06-10]. https://www.iea.org/reports/world-energy-outlook-2017.

[29] ExxonMobil. Outlook for energy: A perspective to 2040 [R/OL]. ExxonMobil, 2019-08-28 [2020-06-10]. https:// corporate.exxonmobil.com/Energy- and- environment/Looking-forward/Outlook-for-Energy.

[30] BP. BP energy outlook [R/OL]. BP, 2017-01-25 [2020-0610]. https://www.bp.com/en/global/corporate/energy-economics/energy-outlook.html.

[31] 王亚栋. 世界能源地缘政治图景: 历史与发展 [J]. 国际 论坛, 2003, 5(2): 1-6. [Wang Yadong. World energy geopolitics landscape: History and development. International Forum, 2003, 5(2): 1-6. ]

[32] 张宇燕, 管清友. 世界能源格局与中国的能源安全 [J]. 世界经济, 2007, 30(9): 17-30. [Zhang Yuyan, Guan Qingyou. World energy pattern and China's energy security. The Journal of World Economy, 2007, 30(9): 17-30. ]

[33] 杨宇, 刘毅. 世界能源地理研究进展及学科发展展望 [J]. 地理科学进展, 2013, 32(5): 818-830. [Yang Yu, Liu Yi. Progress and prospect of world energy geography in China. Progress in Geography, 2013, 32(5): 818-830. ]

[34] 杜德斌, 范斐, 马亚华. 南海主权争端的战略态势及中 国的应对方略 [J]. 世界地理研究, 2012, 21(2): 1-17. [Du Debin, Fan Fei, Ma Yahua. Territorial disputes in the South China Sea and China's strategies. World Regional Studies, 2012, 21(2): 1-17. ]

[35] 孙溯源. 国际石油公司研究 [M]. 上海: 上海人民出版 社, 2010. [Sun Suyuan. International oil company research. Shanghai, China: Shanghai People's Publishing House, 2010. ]

[36] 管清友, 何帆. 中国的能源安全与国际能源合作 [J]. 世 界经济与政治, 2007(11): 45-53, 4-5. [Guan Qingyou, He Fan. China's energy security and international energy cooperation. World Economics and Politics, 2007(11): 45-53, 4-5. ]

[37] 菲利普・赛比耶 - 洛佩兹. 石油地缘政治 [M]. 潘革平, 译. 北京: 社会科学文献出版社, 2008. [Lopez P S. Oil geopolitics. Translated by Pan Geping. Beijing, China: Social Sciences Literature Publishing House, 2008. ]

[38] Conant M A, Gold F R. The geopolitics of energy [M]. Bould, USA: Westview Press, 1978.

[39] 兹比格纽-布热津斯基. 大棋局: 美国战略的首要地位 及其地缘战略 $[\mathrm{M}]$. 中国国际问题研究所, 译. 上海: 上 海人民出版社, 2007. [Zbigniew Brzezinski. The grand chessboard: American primacy and its geostrategic imperatives. Translated by China Institute of International 
Studies. Shanghai, China: Shanghai People's Publishing House, 2007. ]

[40] Klare M T. Resource wars: The new landscape of global conflict [M]. New York, USA: Macmillan Publishers, 2001.

[41] Tuncay Babali. Energy diplomacy in the Caspian basin: Since the end of the cold war [D]. Houston, USA: University of Houston, 2003.

[42] Yergin D. It's still the one [J]. Foreign Policy, 2009, 19: 89-95.

[43] Engdahl F W. Syria, Turkey, Israel and the Greater Middle East energy war [R/OL]. Voltaire Network, 2012-1012 [2020-11-10]. https://www.voltairenet.org/article176200. html.

[44] 杨宇, 刘毅, 金凤君. 能源地缘政治视角下中国与中亚 一俄罗斯国际能源合作模式 [J]. 地理研究, 2015, 34 (2): 213-224. [Yang Yu, Liu Yi, Jin Fengjun. Study on energy cooperation between China and the Central Asia and Russia under the view of energy geopolitics. Geographical Research, 2015, 34(2): 213-224. ]

[45] 让. 雅克. 贝雷比. 世界战略中的石油 [M]. 时波, 等译. 北京: 新华出版社, 1980. [Berebi J J. Oil in the world strategy. Translated by Shi Bo, et al. Beijing, China: Xinhua Publishing House, 1980. ]

[46] 徐建山. 论油权: 初探石油地缘政治的核心问题 [J]. 世 界经济与政治, 2012(12): 115-132, 159-160. [Xu Jianshan. Oil power: The core of oil geopolitics. World Economics and Politics, 2012(12): 115-132, 159-160. ]

[47] 李卓. 石油战略储备与能源利用效率对石油消费的动 态影响 [J]. 数量经济技术经济研究, 2005, 22(6):11-22. [Li Zhuo. Strategic reserve, efficiency of technology and the diversification of energy consumption. Quantitative \& Technica Economics, 2005, 22(6): 11-22. ]

[48] 赵宏图. 世界能源格局的变化与调整 [J]. 国际石油经 济, 2006, 14(10): 17-22, 71. [Zhao Hongtu. Reshaping of the global energy landscape. International Petroleum Economics, 2006, 14(10): 17-22, 71. ]

[49] 唐旭, 冯连勇, 赵林. 基于广义翁氏模型的世界石油供 应格局预测 [J]. 资源科学, 2009, 31(2): 238-242. [Tang $\mathrm{Xu}$, Feng Lianyong, Zhao Lin. Prediction and analysis of world oil supply pattern based on Generalized Weng's Model. Resources Science, 2009, 31(2): 238-242. ]

[50] 李兵, 高波, 葛家理, 等. 石油安全: 中国经济可持续发 展的保障 $[\mathrm{J}$ ]. 人民论坛, 2004(5): 12-15. [Li Bing, Gao Bo, Ge Jiali, et al. Oil security: The guarantee of China's sustainable economic development. People Forum, 2004 (5): 12-15. ]

[51] 李岩, 王礼茂. 从地缘政治角度看中国石油进口运输安
全 [J]. 资源科学, 2008, 30(12): 1784-1790. [Li Yan, Wang Limao. The security of China's oil-importing transportation from the perspective of geopolitics. Resources Science, 2008, 30(12): 1784-1790. ]

[52] 徐小杰. 新世纪的油气地缘政治: 中国面临的机遇与挑 战 [M]. 北京: 社会科学文献出版社, 1998. [Xu Xiaojie. Geopolitics of oil and gas in the new century: Opportunities and challenges facing China. Beijing, China: Social Sciences Literature Publishing House, 1998. ]

[53] 何一鸣, 马丽娟. 世界石油资源格局及中国的应对策略 [J]. 国际经贸探索, 2006, 22(4): 9-11, 16. [He Yiming, Ma Lijuan. On the patterns of the world oil resources and China's countermeasures. International Economics and Trade Research, 2006, 22(4): 9-11, 16. ]

[54] 王恒, 廖勇. 金融危机中的世界能源秩序与我国能源外 交 [J]. 西南科技大学学报(哲学社会科学版), 2010, 27 (6): 34-38. [Wang Heng, Liao Yong. The world energy order and China's energy diplomacy in the financial crisis. Journal of Southwest University of Science and Technology (Philosophy and Social Science Edition), 2010, 27 (6): 34-38. ]

[55] 郝丽莎, 赵媛. 世界石油资源空间分布格局演化分析 [J]. 自然资源学报, 2010, 25(11): 1897-1906. [Hao Lisha, Zhao Yuan. Spatial distribution pattern of global oil resources and its evolution. Journal of Natural Resources, 2010, 25(11): 1897-1906. ]

[56] Maull H W. Energy [M]// Maull H W. Raw materials, energy and western security. London, UK: Palgrave Macmillan, 1984: 50-182.

[57] Stares P B. Rethinking energy security in East Asia [M]. Tokyo, Japan: The Japan Center for International Exchange, 2000.

[58] 周大地, 朱兴珊. 我国石油供应形势和资源及安全战略 [J]. 国际石油经济, 2002(10): 22-26, 71. [Zhou Dadi, Zhu Xingshan. China's strategy to secure oil supply and resources. International Petroleum Economics, 2002(10): 22-26, 71. ]

[59] Yergin D. The quest: Energy, security, and the remaking of the modern world [M]. New York, USA: Penguin Books, 2012.

[60] Marafi K. Security concerns in the Middle East for oil supply: Problems and solutions $[\mathrm{M} / \mathrm{OL}] / /$ Stec S, Baraj B. Energy and environmental challenges to security. Berlin, Germany: Springer, 2009. doi: 10.1007/978-1-40209453-8_15

[61] Lévêque F, Glachant J M, Barquin J, et al. Security of energy supply in Europe [M]. Cheltenham, UK: Edward Elgar Publishing, 2010. 
[62] Thomas R G C, Ramberg B. Energy and security in the industrializing world $[\mathrm{M}]$. Lexington, USA: The University Press of Kentucky, 1990.

[63] 贝尔格雷夫, 等. 2000 年的能源安全 [M]. 王能全, 等 译. 北京: 时事出版社, 1990. [Bejgrav R, et al. Energy security to 2000. Translated by Wang Nengquan, et al. Beijing, China: Current Affairs Press, 1990. ]

[64] Yergin D. Energy security in the 1990s [J]. Foreign Affairs, 1998, 67(1): 111-132.

[65] National Energy Policy Development Group. National energy policy report [R]. Washington D C, USA, 2011.

[66] 罗伯特. 布莱斯. 能源独立之路 [M]. 陆妍, 译. 北京: 清 华大学出版社, 2010. [Bryce R. The dangerous delusions of energy independence. Translated by Lu Yan. Beijing, China: Tsinghua University Press, 2010. ]

[67] 小约瑟夫 - 奈. 理解国际冲突: 理论与历史 [M]. 张小 明, 译. 上海: 上海人民出版社, 2005. [Nye J S Jr. Understanding international conflicts Understanding international conflicts. Translated by Zhang Xiaoming. Shanghai, China: Shanghai People's Publishing House, 2005. ]

[68] 罗伯特 - 基欧汉, 约瑟夫 ·奈. 权力与相互依赖 [M]. 门 洪华, 译. 北京: 北京大学出版社, 2002. [Keohane R, Nye J. Power and interdependence. Translated by Men Honghua. Beijing, China: Peking University Press, 2002. ]

[69] 周冉. 中国 “外源性” 能源安全威胁研究: 基于非传统安 全视角的识别、评估与应对 [J]. 世界经济与政治论坛, 2017(1): 75-97. [Zhou Ran. Research on China's "exogenous" energy security threat: Identification, evaluation and response based on non-traditional security perspectives. Forum of World Economics \& Politics, 2017(1): 75-97. ]

[70] World Energy Council. World Energy Assessment: Energy and the challenge of sustainability [R]. New York, USA, 1995.

[71] 张雷. 中国能源安全问题探讨 [J]. 中国软科学, 2001 (4): 7-12. [Zhang Lei. Discussion about the energy security of China. China Soft Science, 2001(4): 7-12. ]

[72] 安维华. 中国与中东的能源合作 [J]. 西亚非洲, 2001 (1): 12-17. [An Weihua. China's energy cooperation with middle east. West Asia and Africa, 2001(1): 12-17. ]

[73] 吴巧生, 王华, 成金华. 中国可持续发展油气资源安全 态势 [J]. 中国工业经济, 2003(12): 48-56. [Wu Qiaosheng, Wang Hua, Cheng Jinhua. Sustainable developing oil and gas resource security situation in China. China Industrial Economy, 2003(12): 48-56. ]

[74] 中国能源发展战略与政策研究课题组. 中国能源发展 战略与政策研究 [M]. 北京: 经济科学出版社, 2004.
[China Energy Development Strategy and Policy Research Group. Research on national energy comprehensive strategy and policy of China. Beijing, China: Economic Science Press, 2004. ]

[75] 杨东辉. 石油安全战略探析 [J]. 学术交流, 2006(1): 8892. [Yang Donghui. Oil security strategy research. Academic Exchange, 2006(1): 88-92. ]

[76] 吴否. 中国石油安全 [M]. 北京: 中国社会科学出版社, 2003. [Wu Lei. China's oil security. Beijing, China: China Social Sciences Press, 2003. ]

[77] 郎一环, 王礼茂. 石油地缘政治格局的演变态势及中国 的政策响应 [J]. 资源科学, 2008, 30(12): 1778-1783. [Lang Yihuan, Wang Limao. Evolution of petroleum geopolitical patterns and China's policy response. Resources Science, 2008, 30(12): 1778-1783. ]

[78] 任重远, 邵江华. “沙特阿拉伯 2030 愿景”下的中沙油气 合作展望 [J]. 国际石油经济, 2016, 24(10): 53-59. [Ren Chongyuan, Shao Jianghua. The prospect of China-Saudi Arabia oil \& gas cooperation under "Saudi Arabia's vision 2030". International Petroleum Economics, 2016, 24 (10): 53-59. ]

[79] 徐玲琳, 王强, 李娜, 等. 20 世纪 90 年代以来世界能源 安全时空格局演化过程 [J]. 地理学报, 2017, 72(12): 2166-2178. [Xu Linglin, Wang Qiang, Li Na, et al. Spatial- temporal evolution of global energy security since 1990s. Acta Geographica Sinica, 2017, 72(12): 21662178. ]

[80] 王礼茂. 中国资源安全战略: 以石油为例 [J]. 资源科 学, 2002, 24(1): 5-10. [Wang Limao. Resources security strategies in China: The case of oil resources. Resources Science, 2002, 24(1): 5-10. ]

[81] 杜德斌, 段德忠, 刘承良, 等. 1990年以来中国地理学之 地缘政治学研究进展 [J]. 地理研究, 2015, 34(2): 199212. [Du Debin, Duan Dezhong, Liu Chengliang, et al. Progress of geopolitics of Chinese geography since 1990. Geographical Research, 2015, 34(2): 199-212. ]

[82] 渠立权, 骆华松, 胡志丁, 等. 中国石油资源安全评价及 保障措施 [J]. 世界地理研究, 2017, 26(4): 11-19. [Qu Liquan, Luo Huasong, Hu Zhiding, et al. Security evaluation of oil resources and measures on safeguard. World Regional Studies, 2017, 26(4): 11-19. ]

[83] 刘立涛, 沈镭, 高天明, 等. 中国能源安全评价及时空演 进特征 [J]. 地理学报, 2012, 67(12): 1634-1644. [Liu Litao, Shen Lei, Gao Tianming, et al. Evaluation and spatial-temporal evolution of energy security in China. Acta Geographica Sinica, 2012, 67(12): 1634-1644. ]

[84] 胡志丁, 葛岳静, 徐建伟. 尺度政治视角下的地缘能源 安全评价方法及应用 [J]. 地理研究, 2014, 33(5): 853- 
862. [Hu Zhiding, Ge Yuejing, Xu Jianwei. Geopolitical energy security evaluation method and its application based on politics of scale. Geographical Research, 2014, 33(5): 853-862. ]

[85] 沈镭, 薛静静. 中国能源安全的路径选择与战略框架 $[\mathrm{J}]$. 中国人口・资源与环境, 2011, 21(10): 49-54. [Shen Lei, Xue Jingjing. Development path choice and strategy framework of China's energy security. China Population, Resources and Environment, 2011, 21(10): 49-54. ]

[86] 吴磊. 中国能源安全面临的战略形势与对策 [J]. 国际 安全研究, 2013, 31(5): 62-75, 157. [Wu Lei. China's energy security: New challenges and possible solutions. Journal of International Security Studies, 2013, 31(5): 6275, 157. ]

[87] 杨宇, 何则. 构建中国与中亚能源合作政策保障机制 [N]. 中国能源报, 2017-11-13(5). [Yang Yu, He Ze. Construction of mechanism for energy cooperation between China and Central Asia. China Energy News, 2017-11-13 (5). ]

[88] 毛汉英. 中国与俄罗斯及中亚五国能源合作前景展望 [J]. 地理科学进展, 2013, 32(10): 1433-1443. [Mao Hanying. Prospects of energy cooperation of China with Russia and Central Asian countries. Progress in Human Geography, 2013, 32(10): 1433-1443. ]

[89] 赵庆寺. 中国参与 $\mathrm{G} 20$ 全球能源治理的策略选择 [J]. 当 代世界与社会主义, 2015(6): 132-138. [Zhao Qingsi. China's participation in the G20's strategy for global energy governance. Contemporary World \& Socialism, 2015 (6): 132-138. ]

[90] 刘建文, 廖欣. 中国一东盟能源合作及区域性能源安全 体系的构建 [J]. 学术论坛, 2016, 39(11): 52-57, 98. [Liu Jianwen Liao xin. Construction of China- ASEAN energy cooperation and regional energy security system. Academic Forum, 2016, 39(11): 52-57, 98. ]

[91] 间世刚, 刘曙光. 新能源安全观下的中国能源外交 [J]. 国际问题研究, 2014(2): 109-117. [Yan Shigang, Liu Shuguang. China's energy diplomacy under the new energy security concept. International Studies, 2014(2): 109117. ]

[92] 威廉・恩道尔. 石油大棋局: 下一个目标中国 [M]. 戴 健, 李峰, 顾秀林, 译. 北京: 中国民主法制出版社, 2011. [Engdahl F W. The new energy world. Translated by Dai Jian, Li Feng, Gu Xiulin. Beijing, China: China Democratic Legal Press, 2011. ]

[93] 夏义善. 中国国际能源发展战略研究 [M]. 北京: 世界 知识出版社, 2009. [Xia Yishan. China's perspective on international energy development strategy. Beijing, China: World Affairs Press, 2009. ]
[94] 黄运成, 陈志斌. 高油价时代的国际石油地缘政治与中 国石油贸易格局 [J]. 资源科学, 2007, 29(1): 172-177. [Huang Yuncheng, Chen Zhibin. Oil geopolitics in high price and China's oil trade patterns. Resources Science, 2007, 29(1): 172-177. ]

[95] Yang Y, Poon J P H, Liu Y, et al. Small and flat worlds: A complex network analysis of international trade in crude oil [J]. Energy, 2015, 93: 534-543.

[96] Serrano M A, Boguñá M. Topology of the world trade web [J]. Physical Review E: Statistical, Nonlinear, and Soft Matter Physics, 2003, 68(1): 015101. doi: 10.1103/ PhysRevE.68.015101.

[97] Garlaschelli D, Loffredo M I. Structure and evolution of the world trade network [J]. Physica A: Statistical Mechanics and Its Applications, 2005, 355(1): 138-144.

[98] Fagiolo G, Reyes J, Schiavo S. The evolution of the world trade web: A weighted-network analysis [J]. Journal of Evolutionary Economics, 2010, 20(4): 479-514.

[99] Gao X G, An H Z, Zhong W Q. Features of the correlation structure of price indices [J]. PLoS ONE, 2013, 8(4): e61091. doi: 10.1371/journal.pone.0061091.

[100] Ji Q, Zhang H Y, Fan Y. Identification of global oil trade patterns: An empirical research based on complex network theory $[\mathrm{J}]$. Energy Conversion and Management, 2014, 85: 856-865.

[101] 安海忠, 陈玉蓉, 方伟, 等. 国际石油贸易网络的演化 规律研究: 基于复杂网络理论 [J]. 数学的实践与认 识, 2013, 43(22): 57-64. [An Haizhong, Chen Yurong, Fang Wei, et al. Research on the evolution of the international oil trade network. Mathematics in Practice and Theory, 2013, 43(22): 57-64. ]

[102] An H Z, Zhong W Q, Chen Y R, et al. Features and evolution of international crude oil trade relationships: A trading-based network analysis [J]. Energy, 2014, 74: 254-259.

[103] Kitamura T, Managi S. Driving force and resistance: Network feature in oil trade [J]. Applied Energy, 2017, 208: 361-375.

[104] 何则, 杨宇, 刘毅, 等. 世界能源贸易网络的演化特征 与能源竞合关系 [J]. 地理科学进展, 2019, 38(10): 1621-1632. [He Ze, Yang Yu, Liu Yi, et al. Characteristics of evolution of global energy trading network and relationships between major countries. Progress in Geography, 2019, 38(10): 1621-1632. ]

[105] Shao Y M, Qiao H, Wang S Y. What determines China's crude oil importing trade patterns? Empirical evidences from 55 countries between 1992 and 2015 [J]. Energy Policy, 2017, 109: 854-862. 
[106] Guan Q, An H Z, Gao X Y, et al. Estimating potential trade links in the international crude oil trade: A link prediction approach [J]. Energy, 2016, 102: 406-415.

[107] 孙琪, 赵媛, 张新林, 等. “一带一路”沿线国家石油资 源流动类型演变 [J]. 世界地理研究, 2020, 29(2): 337345. [Sun Qi, Zhao Yuan, Zhang Xinlin, et al. The evolution of the types of petroleum resources flow in the countries along "Belt and Road". World Regional Studies, 2020, 29(2): 337-345. ]

[108] Zhang H Y, Ji Q, Fan Y. What drives the formation of global oil trade patterns? [J]. Energy Economics, 2015, 49: 639-648.

[109] Yang Y, Dong W. Global energy networks: Insights from headquarter subsidiary data of transnational petroleum corporations [J]. Applied Geography, 2016, 72: $36-46$.

[110] Zhong W Q, An H Z, Gao X Y, et al. The evolution of communities in the international oil trade network [J]. Physica A: Statistical Mechanics and Its Applications, 2014, 413: 42-52.

[111] Sun Q R, Gao X Y, Zhong W Q, et al. The stability of the international oil trade network from short-term and long-term perspectives [J]. Physica A: Statistical Mechanics and Its Applications, 2017, 482: 345-356.

[112] Wang S G, Chen B. Hybrid ecological network and flow-distance analysis for international oil trade [J]. Energy Procedia, 2016, 104: 209-214.

[113] Du R J, Wang Y, Dong G G, et al. A complex network perspective on interrelations and evolution features of international oil trade, 2002-2013 [J]. Applied energy, 2017, 196: 142-151.

[114] Zhang H Y, Ji Q, Fan Y. Competition, transmission and pattern evolution: A network analysis of global oil trade [J]. Energy Policy, 2014, 73: 312-322.

[115] 赵媛, 沈绿等, 郝丽莎. “丝绸之路经济带” 在世界石油 供给格局中的地位及演变 [J].自然资源学报, 2016, 31 (5): 732-742. [Zhao Yuan, Shen Lüyun, Hao Lisha. The status of Silk Road Economic Belt in the world oil supply pattern and its evolution. Journal of Natural Resources, 2016, 31(5): 732-742. ]

[116] Du R J, Dong G G, Tian L X, et al. A complex network perspective on features and evolution of world crude oil trade [J]. Energy Procedia, 2016, 104: 221-226.

[117] 程中海, 南楠, 张亚如. 中国石油进口贸易的时空格 局、发展困境与趋势展望 [J]. 经济地理, 2019, 39(2): 1-11. [Cheng Zhonghai, Nan Nan, Zhang Yaru. The spatio- temporal pattern, development predicament and trend of China's petroleum import trade. Economic Ge- ography, 2019, 39(2): 1-11. ]

[118] 杨金金, 安海忠, 高湘昀. 国际天然气贸易关系网络结构 特征研究: 基于复杂网络理论 [J]. 资源与产业, 2012, 14(2): 81-87. [Yang Xin, An Haizhong, Gao Xiangyun. Structural features of global gas trading relationship network based on complex network theory. Resources \& Industries, 2012, 14(2): 81-87. ]

[119] 肖建忠, 彭莹, 王小林. 天然气国际贸易网络演化及区 域特征研究: 基于社会网络分析方法 [J]. 中国石油大 学学报(社会科学版), 2013, 29(3): 1-8. [Xiao Jianzhong, Peng Ying, Wang Xiaolin. On the evolution of natural gas international trade network and regional variations. Journal of China University of Petroleum (Edition of Social Sciences), 2013, 29(3): 1-8. ]

[120] Geng J B, Ji Q, Fan Y. A dynamic analysis on global natural gas trade network [J]. Applied Energy, 2014, 132: 23-33.

[121] 张宏, 王礼茂, 宋涛, 等. 面向全空间的管道天然气贸 易关联关系挖掘 [J]. 地球信息科学学报, 2017, 19(9): 1253-1260. [Zhang Hong, Wang Limao, Song Tao, et al. Mining of association relationship of the pan spatialoriented trade of pipeline natural gas. Journal of Geo-information Science, 2017, 19(9): 1253-1260. ]

[122] 马远, 徐俐俐. “一带一路”沿线国家天然气贸易网络 结构及影响因素 [J]. 世界经济研究, 2017(3): 109122, 136. [Ma Yuan, Xu Lili. Network structure and influence factors of gas trade about the countries along "the Belt and Road". World Economy Studies, 2017(3): 109-122, 136. ]

[123] 赵亚博, 刘晓凤, 葛岳静. “一带一路”沿线国家油气资 源分布格局及其与中国合作中的相互依赖关系 [J]. 地理研究, 2017, 36(12): 2305-2320. [Zhao Yabo, Liu Xiaofeng, Ge Yuejing. Analysis of the oil and gas resource distribution pattern along the Belt and Road and the interdependence relationship with China. Geographical Research, 2017, 36(12): 2305-2320. ]

[124] Üster H, Dilaveroğlu Ş. Optimization for design and operation of natural gas transmission networks $[\mathrm{J}]$. Applied Energy, 2014, 133: 56-69.

[125] Chen Z H, An H Z, Gao X Y, et al. Competition pattern of the global liquefied natural gas (LNG) trade by network analysis $[\mathrm{J}]$. Journal of Natural Gas Science and Engineering, 2016, 33: 769-776.

[126] Feng S, Li H, Qi Y, et al. Who will build new trade relations? Finding potential relations in international liquefied natural gas trade [J]. Energy, 2017, 141: 1226-1238.

[127] 杨宇, 王礼茂, 江东, 等. 美国对伊朗石油禁运与全球 能源安全 [J]. 地理研究, 2018, 37(10): 1879-1898. 
[Yang Yu, Wang Limao, Jiang Dong, et al. U.S. sanctions policy on Iran's oil export and its influence on global energy security. Geographical Research, 2018, 37 (10): 1879-1898. ]

[128] 梁甲瑞. 印度海上战略通道的新动向、动因及影响 [J]. 世界地理研究, 2020, 29(1): 52-62. [Liang Jiarui. Tendency, motivation and influence of India's marine strategic access. World Regional Studies, 2020, 29(1): 52-62. ]

[129] 吴良, 秦奇, 张丹, 等. 印度洋通道及其对中国地缘环 境影响 [J]. 地理科学进展, 2018, 37(11): 1510-1520. [Wu Liang, Qin Qi, Zhang Dan, et al. Indian Ocean Passages and their geopolitical impacts on China. Progress in Geography, 2018, 37(11): 1510-1520. ]

[130] Yan Z J, Xiao Y J, Cheng L, et al. Analysis of global marine oil trade based on automatic identification system (AIS) data [J]. Journal of Transport Geography, 2020, 83: 102637. doi: 10.1016/j.jtrangeo.2020.102637.

[131] Peng P, Yang Y, Cheng S F, et al. Hub-and-spoke structure: Characterizing the global crude oil transport network with mass vessel trajectories [J]. Energy, 2019, 168: 966-974.

[132] Peng P, Poon J P H, Yang Y, et al. Global oil traffic network and diffusion of influence among ports using real time data [J]. Energy, 2019, 172: 333-342.

[133] 王武林, 余翠婵, 王成金. 俄罗斯东北航道沿线港口发 展潜力评价 [J]. 世界地理研究, 2019, 28(6): 22-31. [Wang Wulin, Yu Cuichan, Wang Chengjin. Evaluation of port development potential along the Northern Sea Route in Russia. World Regional Studies, 2019, 28(6): 22-31. ]

[134] 王伟, 王成金, 金风君. 基于货物结构的中国沿海港口 运输职能判别 [J]. 地理研究, 2018, 37(3): 527-538. [Wang Wei, Wang Chengjin, Jin Fengjun. The classification of transportation function of China's coastal Ports based on cargo structure. Geographical Research, 2018, 37(3): 527-538. ]

[135] 王诺, 田玺环, 赵伟杰. 基于 “海上丝绸之路”通道安全 的海外港口战略布局研究 [J]. 世界地理研究, 2019, 28(5): 74-82. [Wang Nuo, Tian Xihuan, Zhao Weijie. The strategic layout of the overseas ports based on the channel security of the Maritime Silk Road. World Regional Studies, 2019, 28(5): 74-82. ]

[136] Peng P, Yang Y, Lu F, et al. Modelling the competitiveness of the ports along the Maritime Silk Road with big data [J]. Transportation Research Part A: Policy and Practice, 2018, 118: 852-867.

[137] Yang Y, Poon J P, Dong W. East Asia and solar energy trade network patterns [J]. Geographical Review, 2017, 107(2): 276-295

[138] BP. Statistical review of world energy 2017 [R]. London, UK: BP, 2017.

[139] Fu X, Yang Y, Dong W, et al. Spatial structure, inequality and trading community of renewable energy networks: A comparative study of solar and hydro energy product trades [J]. Energy Policy, 2017, 106: 22-31.

[140] Gao C X, Sun M, Shen B. Features and evolution of international fossil energy trade relationships: A weighted multilayer network analysis [J]. Applied Energy, 2015, 156: 542-554.

[141] Guan Q, An H Z. The exploration on the trade preferences of cooperation partners in four energy commodities' international trade: Crude oil, coal, natural gas and photovoltaic [J]. Applied Energy, 2017, 203: 154-163.

[142] Zhong W Q, An H Z, Shen L, et al. Global pattern of the international fossil fuel trade: The evolution of communities [J]. Energy, 2017, 123: 260-270.

[143] Zhong W Q, An H Z, Shen L, et al. The roles of countries in the international fossil fuel trade: An emergy and network analysis [J]. Energy Policy, 2017, 100: 365-376.

[144] Goldthau A, Jan M W. Global energy governance: The new rules of the game $[\mathrm{M}]$. Washington D C, USA: Brookings Institution Press, 2010.

[145] Florini A, Sovacool B K. Bridging the gaps in global energy governance $[\mathrm{J}]$. Global Governance: A Review of Multilateralism and International Organizations, 2011, 17(1): 57-74.

[146] Lesage D, Van de Graaf T. Global energy governance in a multipolar world [M]. London, UK: Routledge, 2016.

[147] 许勤华. G20 峰会为全球能源治理提供中国机会 [J]. 能源研究与利用, 2016(5): 4-5, 8. [Xu Qinhua. The G20 summit provides China with opportunities for global energy governance. Energy Research \& Utilization, 2016(5): 4-5, 8. ]

[148] Sovacool B K, Valentine S V. The national politics of nuclear power: Economics, security, and governance [M]. London, UK: Routledge, 2012.

[149] Cherp A, Jewell J, Goldthau A. Governing global energy: Systems, transitions, complexity [J]. Global Policy, 2011, 2(1): 75-88.

[150] 赵庆寺. 中国参与全球能源治理的问题与对策 $[\mathrm{J}]$. 人 民论坛・学术前沿, 2016(22): 38-48. [Zhao Qingsi. Issues and countermeasures of China's participation in global energy governance. Frontiers, 2016(22): 38-48. ]

[151] IEA. China's engagement in global energy governance, 
IEA partner country series [DB/OL]. 2016-03-31 [202003-11]. https://doi.org/10.1787/9789264255845-en.

[152] 叶玉. 全球能源治理:结构、挑战及走向 [J]. 国际石油 经济, 2011, 19(8): 44-50, 111. [Ye Yu. Global energy governance: Structure, challenges and prospects. International Petroleum Economics, 2011, 19(8): 44- 50, 111. ]

[153] 于宏源. 全球能源治理的功利主义和全球主义 [J]. 国 际安全研究, 2013, 31(5): 76-95, 157-158. [Yu Hongyuan. Globalism and utilitarianism in global energy governance. Journal of International Security Studies, 2013, 31(5): 76-95, 157-158. ]

[154] 孙阳昭, 蓝虹. 全球能源治理的框架、新挑战与改革趋 势 [J]. 经济问题探索, 2013(11): 79-83. [Sun Yangzhao, Lan Hong. The framework, new challenges and reform trends of global energy governance. Inquiry into Economic Issues, 2013(11): 79-83. ]

[155] 潘家华. 负面冲击正向效应: 美国总统特朗普宣布退 出《巴黎协定》的影响分析 $[\mathrm{J}]$. 中国科学院院刊, 2017, 32(9): 1014-1021. [Pan Jiahua. Negative shock but positive effect: Understanding impact of US withdrawal from Paris Climate Agreement. Bulletin of Chinese Academy of Sciences, 2017, 32(9): 1014-1021. ]

[156] 马妍. 全球能源治理变局: 挑战与改革趋势 [J]. 现代 国际关系, 2016(11): 55-62. [Ma Yan. Global energy governance changes: Challenges and reform trends. Contemporary International Relations, 2016(11): 5562. ]
[157] 邹志强. 二十国集团与全球能源治理: 成效与前景 [J]. 国际经济合作, 2015(11): 21-26. [Zou Zhiqiang. G20 and global energy governance: Results and prospects. Journal of International Economic Cooperation, 2015(11): 21-26. ]

[158] 戚凯. 全球能源安全治理: 风险挑战、国际合作与中国 角色 [J]. 国际论坛, 2017, 19(4): 13-18, 79. [Qi Kai. Global governance of energy security: Challenges, international cooperation and China's role. International Forum, 2017, 19(4): 13-18, 79. ]

[159] 黄贤金, 卢芹莉. 世界资源地理研究: 中国资源地理学 的现状、缺失与机遇 [J]. 地理研究, 2016, 35(4): 607616. [Huang Xianjin, Lu Qinli. World resource geography: The present status, deficiency and opportunity of China's resource geography. Geographical Research, 2016, 35(4): 607-616. ]

[160] 国家发改委能源研究所, 英国帝国理工大学葛量洪研 究所. 全球能源治理改革与中国的参与 [M]. 北京: 清 华大学出版社, 2017. [Energy Research Institute in National Development and Reform Commission, Grantham Institute of Imperial College London. Global energy governance reform and China's participation. Beijing, China: Tsinghua University Press, 2017. ]

[161] 赵勇强. 国际可再生能源发展与全球能源治理变革 [J]. 宏观经济研究, 2017(4): 43-54. [Zhao Yongqiang. International renewable energy development and global energy governance reform. Macroeconomics, 2017(4): 43-54. ] 


\title{
Energy geopolitics and power
}

\author{
YANG Yu ${ }^{1,2,3}, \mathrm{HE} \mathrm{Ze}^{1,2,3^{*}}$ \\ (1. Key Laboratory of Regional Sustainable Development Modeling/Institute of Geographic \\ Sciences and Natural Resources Research, CAS, Beijing 100101, China; \\ 2. College of Resources and Environment, University of Chinese Academy of Sciences, Beijing 100049, China; \\ 3. Institute of Strategy Research of Guangdong-Hong Kong-Macao Greater Bay Area, Guangzhou 510070, China)
}

\begin{abstract}
In the new era, oil and gas are still the core contents of energy power games, the attributes of energy power are very different, and the connotation of energy security and energy strategy has also changed. Based on a systematic review of energy geopolitics, this study put forward the concept of energy power, and found that the global energy situation is undergoing profound changes. Instead of taking the "oil power" generated by the possession and production rights of fossil energy as the only core, global energy research has expanded to multidimensional energy power, and the power connection has expanded from competition and cooperation to the complex energy network relationship. The research elaborated specifically from four aspects: geopolitical pattern, energy security concept, energy network, and global energy governance: 1) The core of traditional energy geopolitical research is energy distribution, spatial change of production and marketing, and their patterns, and the imbalance of oil and gas resources geographic distribution is the most direct factor of energy power generation. 2) From the oil crisis era with supply security as the core, to the collective action formed around energy interdependence, and the new order of global energy governance in the new energy era in the future, the different views of energy security are the important factor leading to the change of international energy geopolitical power. 3) Energy as commodity and the geographical attributes of energy determine that energy trade is not only an economic behavior, but also closely related to international politics. The separation of production and consumption makes trade control and channel control in the secondary distribution of oil and gas an important influencing factor on the reconstruction of energy power. 4) The change of global energy power and complex energy power network will lead to a new order of global energy governance system. The main holders of power have changed from countries, international organizations, and multinational companies to communities of interest in the global energy network. The theme of energy governance has changed from the interests of countries to the redistribution process of global energy power. In future studies, academic research of energy geopolitics should focus on the following issues: how to construct a new theory of multi-dimensional energy power system; how to evaluate the influence of new factors such as climate change and renewable and sustainable energy development; how to understand the inter-relationship between energy power and geographic space under globalization; how to reconstruct the order of global energy power and simulate its effect, and how to clarify the new energy governance mechanism and governance patterns. These themes are important energy geopolitics research propositions, and are of great significant for understanding and predicting the future energy situation and change in energy strategies.
\end{abstract}

Keywords: energy geopolitics; energy power; energy security; energy trade; global energy governance 